\title{
Contested Boundaries. Psychiatry, Disease, and Diagnosis
}

\section{Citation}

Rosenberg, Charles. 2006. Contested boundaries. Psychiatry, disease, and diagnosis.

Perspectives in Biology and Medicine 49(3): 407-424.

\section{Published Version}

doi:10.1353/pbm.2006.0046

\section{Permanent link}

http://nrs.harvard.edu/urn-3:HUL.InstRepos:4730323

\section{Terms of Use}

This article was downloaded from Harvard University's DASH repository, and is made available under the terms and conditions applicable to Other Posted Material, as set forth at http:// nrs.harvard.edu/urn-3:HUL.InstRepos:dash.current.terms-of-use\#LAA

\section{Share Your Story}

The Harvard community has made this article openly available.

Please share how this access benefits you. Submit a story.

\section{Accessibility}




\title{
CONTESTED BOUNDARIES
}

\author{
psychiatry, disease, and diagnosis
}

\section{CHARLES E. ROSENBERG}

\begin{abstract}
Since the 19th century, we have come to think of disease in terms of specific entities-entities defined and legitimated in terms of characteristic somatic mechanisms. Since the last third of that century, we have expanded would-be disease categories to include an ever-broader variety of emotional pain, idiosyncrasy, and culturally unsettling behaviors. Psychiatry has been the residuary legatee of these developments, developments that have always been contested at the ever-shifting boundary between disease and deviance, feeling and symptom, the random and the determined, the stigmatized and the value-free. Even in our era of reductionist hopes, psychopharmaceutical practice, and corporate strategies, the legitimacy of many putative disease categories will remain contested. The use of the specific disease entity model will always be a reductionist means to achieve necessarily holistic ends, both in terms of cultural norms and the needs of suffering individuals. Bureaucratic rigidities and stakeholder conflicts structure and intensify such boundary conflicts, as do the interests and activism of an interested lay public.
\end{abstract}

S Ome Years ago, the New York Times front page reported the outcome of a $\checkmark$ much-discussed courtroom drama, the Andrew Goldstein murder trial. Previously diagnosed and treated-or more often not treated-as a chronic schizophrenic, Goldstein had killed a random young woman by pushing her in front

Department of the History of Science, Harvard University, Cambridge, MA 02138.

E-mail: rosenb3@fas.harvard.edu.

The author would like to thank audiences at the University of Alabama-Birmingham, Ohio State, Cornell (Department of Psychiatry), Duke, Harvard, MIT, the University of Pennsylvania, and Rutgers, who provided helpful reactions to earlier versions of this paper, and Robert Aronowitz, Charles Bosk, Drew Faust, Gerald N. Grob, Anne Harrington, David Healy, Arthur Kleinman, David Mechanic, and Rosemary Stevens, who also read and commented on drafts.

Perspectives in Biology and Medicine, volume 49, number 3 (summer 2006):407-24

(C) 2006 by The Johns Hopkins University Press 
of a subway train. Despite his unchallenged diagnosis, the jury convicted Goldstein of second-degree murder. "He seemed to know what he was doing," one juror said after the trial. "He picked her up and threw her. That was not a psychotic jerk, an involuntary movement." Another juror explained that they had thought the defendant was "in control and acted with intent to kill." "It was staged and executed," he said of the lethal attack. "There was forethought and exquisite timing" (Barnes 2000).

This is a story of intellectual and institutional conflict, of inconsistent conceptions of disease and impulse control, and of a chronically ill-starred relationship between law and medicine. It is also a story that might have been written in 1901 as well as in 2001; and, of course, the formal categories of the cognitively defined right-and-wrong test for criminal responsibility still lingers in most American courtrooms. Not too long ago, our media retailed the story of Houston mother Andrea Yates, who drowned her five children. The local prosecutor argued that there was no question concerning her responsibility. She knew right from wrong, he was quoted as saying: "You will also hear evidence that she knew it was an illegal thing, that it was a sin, that it was wrong" (New York Times 2002).

But such highly publicized forensic dramas represent just one-in some ways far from typical-example of a much larger and more pervasive phenomenon: the negotiation of disease in public and the particularly ambiguous status of hypothetical ailments whose presenting symptoms are behavioral or emotional. Most of us would agree that there is some somatic mechanism or mechanisms (whatever their nature or origin) associated with grave and incapacitating psychoses, but as the dilemma of criminal responsibility illustrates, even in such cases we remain far from agreement about management and precise disease boundaries. But there is a much larger group of individuals who represent a more elusive and ambiguous picture. They are men and women who experience incapacitating emotional pain, who have difficulties in impulse control-or who, even if they have not violated a criminal statute, behave in ways that seem socially or morally unacceptable to many of their generational peers.

Sociologists and social critics have, for more than a quarter-century, spoken of the medicalization of deviance, of the tendency to recategorize $\sin (\mathrm{s})$ as pathology(ies) and to consign the management of such conditions to appropriately certified practitioners. ${ }^{1}$ But this is only one subset of a larger phenomenon that is in

\footnotetext{
${ }^{1}$ For a recent sociological overview of the state of play, see Clarke et al. 2003; Conrad 2005; and Horwitz 2002. This is not an essay about the idea of medicalization and its history, but I do want to express a word of caution about the tendency to conceptualize medicalization as a reified, monolithic, and inexorable thing - a point-of-view that obscures the complex, multidimensional, and inconsistent nature of the way in which medical concepts and practices have laid claim to larger realms of social action and authority. Conrad (2005), for example, refers to the role of pharmaceutical companies and managed care as "engines that are driving ... [the] medicalization train ... into the twenty-first century" (p. 12). Trains are material things that move forward in one direction only-along predetermined tracks. For Conrad's earlier formulations, see Conrad 1976 and Conrad and Schneider 1992.
} 
a literal sense coterminous with the history of medicine as a specialized calling. I refer to the assignment of certain aspects of human pain and incapacity to the realm of medicine and to the physician's care and explanatory authority. "Medicalization" might perhaps be better understood as a long-term trend in Western society toward reductionist, somatic, and - increasingly — disease-specific explanations of human feelings and behavior as well as unambiguously physical ills.

Nevertheless, the phenomenon remains complex, inconsistent, and contingent, even if expansive and increasingly pervasive. The relationships among disease concepts and painful or socially problematic behaviors have been and are being contested and recontested, not only in melodramatic courtroom situations, but in countless clinical, bureaucratic, and administrative contexts. Moreover, deviance is hardly a discrete and objective thing: it is time-, place-, and even class-specific. Think of now casually accepted sexual behaviors that a century ago would have been seen as certainly deviant and possibly pathognomonic-ranging from masturbation to "excessive" female sexuality. A bright line between disease and willed misbehavior or culpable self-indulgence-or idiosyncratic emotional discomfort-will not easily be agreed upon, while the cultural and bureaucratic need to create such boundaries will hardly disappear. Meanwhile individual men and women, lay and professional, act out complex and not always consistent agendas shaped by personal, familial, generational, and social locational realities.

Criminal responsibility and the vexed relationship between law and medicine constitute only one such area of recurring negotiation. The media provide countless instances of such public controversy, only a very small minority of which are acted out in criminal courts. I need only refer to a number of problematic categories, entities such as gender identity disorder, attention deficit hyperactivity disorder, social anxiety disorder, or chronic fatigue syndrome, not to mention road rage and premenstrual syndrome or putatively-and thus potentially exculpatory-pathological addictions to gambling and sex. A local outpatient psychiatric facility has recently offered treatment for "computer addiction" - an inability to refrain from the internet (McLean Hospital n.d.). Readers are informed that the hospital offers a full range of "specialized clinical programs in addition to those for computer addiction ... [including] . . . those dealing with anxiety, depression, alcohol and drug abuse, Alzheimer's, dementia, personality disorders, bipolar and psychotic illnesses, dissociative disorders, trauma, sleep disorders, human sexuality, and women's and men's issues."

Public policy in regard to drug and alcohol use represents another tenaciously contested occasion for debating the applicability and legitimacy of disease concepts. Billions of dollars and many thousands of lives have been altered by deeply felt and widely disseminated assumptions concerning what has come to be called substance abuse. Are such behaviors the symptoms of a chronic disease (with a biochemical and perhaps genetic substrate) that demands treatment? Or are they crimes to be punished? "Addiction is a chronic disease that demands a medical 
and public health response," one advocate of the disease model contended in a typical letter to the editor. "It is not a moral lapse" (Boston Globe 2001). Such conflicts surrounding the ontological status - and thus social legitimacy-of behavioral and emotional ills have been endemic since their widespread articulation well over a century ago. Patterns of cultural and clinical visibility change, but that ambiguity remains; today, for example, problems of mood constitute a particularly pervasive and diagnostically tendentious category. Is depression a thing? Or a dimension of human diversity and the human condition? Andor-an appropriate response to situational realities? These questions have become all too familiar in the past generation.

Perhaps the most embarrassingly public of such debates over the epistemological legitimacy of a disease category took place more than a generation ago and was occasioned by a planned revision of the American Psychiatric Association's Diagnostic and Statistical Manual. In retrospect, the most egregious aspect of this conflict was the series of votes surrounding a reconsideration of the problematic category "homosexuality." Was this a disease? Or a choice? And how could a legitimate disease-in most physician's minds a biological phenomenon with a characteristic mechanism and predictable course-be decided by a vote? A vote, moreover, influenced by feverish lobbying and public demonstrations (Bayer 1987). Though it has become routine, many Americans still find it unseemly that diagnoses can be shaped in part by advocacy groups and Web sites, or that disease-targeted research funding can be determined in part by lobbyists, lay advocates, and journalists, and not by the seemingly objective and inexorable logic of laboratory findings. (Although lobbying for federal support of cancer research and treatment has come to seem normal politics, a similar worldly judgment seems not so easily accepted when applied to ailments of mood and behavior.) And in the private sector, we have seen in the past half-century how pharmaceutical industry research and marketing decisions have helped reshape both medical and lay notions of emotional illness and its treatment. But we have also witnessed the articulation of a vigorous critique of such trends, a criticism not only of specific corporate tactics, but also of the social role of business, its relationship to government, and of the problematic nature of psychiatry's diagnostic categories. $^{2}$

What I should like to do in the following pages is to outline the key characteristics of an era of expanding nosological boundaries-beginning in roughly the last third of the 19th century and extending into the present-and then specify some of the reasons that controversy often continues to surround disease categories that promise to explain behavior and emotional pain. ${ }^{3}$ Much of what

\footnotetext{
${ }^{2}$ David Healy (1997) has been particularly influential in his linkage of pharmaceutical company strategies with a shift in psychiatric nosology and clinical practice.

${ }^{3}$ Many of these generalizations might be seen as applying to chronic disease as well, in which the stigmatization of cultural deviance is transformed into the seemingly neutral language of risk, and
} 
I will be discussing falls into psychiatry's domain of clinical responsibility. For more than a century, the psychiatrist has been the designated trustee of those social and emotional dilemmas that can plausibly — and thus usefully-be framed as the product of disease. We contest the precise definitions and appropriate clinical and social responses to somatic ills as well, but behavioral and emotional ailments constitute a particularly sensitive and contingent subset of problems. Since its origins as a specialty in the 19th century, psychiatry has been a definer of boundaries, a delineator and designated manager of the normal and abnormal, and thus unavoidably a key participant in this never-ending debate. At the same time it has suffered from a recurrent status anxiety - one might call it procedure envy, or organic inferiority. Psychiatry has been chronically sensitive to its inability to call upon a repertoire of tightly bounded, seemingly objective, and generally agreed-upon diagnostic categories based firmly on biopathological mechanisms (Grob 1998). Ailments such as pellagra and paresis, which had been the psychiatrist's responsibility when their cause and treatment was obscure, left the specialty's domain when their mechanisms were understood and their treatment established. Psychiatry remains the legatee of the emotional, the behavioral, and the imperfectly understood. In this sense it has been a poor relation of its specialist peers in surgery and internal medicine. And one need hardly speak of psychiatry's history of uncritical flirtations with seemingly effective somatic interventions. ${ }^{4}$ Think, for example, of insulin shock and lobotomy.

\section{THE SPECIFICITY TRAP}

Though diverse, the examples of contested ills I have cited exhibit a number of core similarities. All illustrate the social and intellectual centrality of specific disease entities and the assumption that a legitimate disease is discrete and that it has a characteristic clinical course; perhaps equally important, behavioral and emotional symptoms are presumed to reflect an underlying mechanism. In other words, what some sociologists and social critics have for decades called "medicalization" is in practice the use of time- and place-specific vocabularies of disease entities as a tool for at once conceptualizing and managing behavior and feelings. And these disease models have ultimately to be specific and somatic if they are to find wide acceptance.

\footnotetext{
(continued) in which agency and the discussion of behavior in the form of lifestyle management becomes central (Rosenberg 1995).

${ }^{4}$ As one advocate for the specialty put it in 1902: "The work done by the alienist cannot remain long in the condition in which it is at present and still be considered worthy of respect by members of other branches of the medical profession" (Paton 1902, p. 434). Not surprisingly, he called not only for a parity in the treatment of mental illness with that available for typhoid fever or pneumonia sufferers, but also for investment in high-status physical chemistry and a sharpening of the alienist's embarrassingly vague diagnostic categories. After all, psychiatry was presented with problems "involving .... all questions for the preservation and continuance of the normal mental activities in a community" (p. 442).
} 
A somatic identity is perhaps most fundamental. It is no accident that today's advocates for the mentally ill state again and again that "it" is a physical ailment no different from diabetes or cancer-and no more deserving of censure or lessthan-equal insurance coverage. "The brain is an organ," as a New York Times (1999) editorialist put it in formulaic language, "and diseases related to this organ should be treated like any other medical illness." It was no wonder that President Clinton should have described it as "morally right" for insurance companies to set the same annual and lifetime coverage limits for mental as for physical ills. Like the rules of criminal responsibility, insurance coverage presents a continuing occasion for debating the nature and treatment of emotional and behavioral ills. It is also not surprising that such claims inevitably generate not only novel entities, but also — and equally important — somatic rationalizations for the existence of such ailments. As I edited this paper, for example, my morning newspaper reported that "a national study ... reported that at some point in their lives, about 5 per cent of people have such frequent, serious blow-ups that they qualify as suffering from Intermittent Explosive Disorder, a full-fledged psychiatric diagnosis." The reporter also cited the comments of an authority on anger: "It's not simply bad behavior," the expert explained: "There's a biology and a psychology and a genetics and a neuroscience behind this, and you can come up with strategies for intervention just like for anything else, like diabetes or hypertension or depression" (Goldberg 2005). All such examples - and one could cite hundreds of others from contemporary print and electronic sources-reflect the underlying historical reality I have already discussed: the cultural pervasiveness of somatic, mechanism-based ideas of disease specificity, and the problems associated with using such concepts to manage deviance, rationalize idiosyncrasy, and explain emotional pain.

I have been interested for many years in the history of such putative disease categories (Rosenberg 2002, 2003). One theme that seems to me particularly fundamental is the idea of disease specificity itself - the notion that diseases can and should be thought of as entities existing outside their unique manifestations in particular men and women. These ideas did not become culturally pervasive until the last third of the 19th century. And, not so coincidentally, it was only in this period that such hypothetical disease entities began to be used widely and routinely to explain an increasing variety of socially stigmatized or self-destructive behaviors. Of course, there are earlier examples of similar phenomena: even non-historians have come across such conditions as hypochondriasis, hysteria, and melancholy, and references in literature to a variety of painful moods explained in terms of a speculative but materialist pathophysiology. Humoral explanations of temperamental peculiarity are as old as Western medicine itself, but the disease concepts they rationalized were fundamentally different from those most of us take for granted today. Conditions such as melancholy or hysteria were as much flexible descriptions of individual life-course outcomes as diseases conceived of in terms of modern notions of specificity. 
The late 19th century was an era of expanding clinical boundaries — a period in which hypothetical ailments such as homosexuality, kleptomania, neurasthenia, railroad spine, and anorexia were delineated-one might say put into cultural play-as disease entities. Some of these terms persist, while others have an archaic ring or altered meanings, yet all were described as novel clinical phenomena by enthusiastic late-19th-century physicians. The timing is no accident. The first three quarters of the century had provided a series of intellectual building blocks, cumulatively suggesting a new emphasis on disease as discrete entity. Earlier interest in clinical description and postmortem pathology had articulated and disseminated a lesion-based notion of disease, but the late 19th century saw a hardening in this way of thinking, reflecting the assimilation of germ theories of infectious disease as well as a variety of findings from the laboratories of physiologists and biochemists. The gradual assimilation of the notion that specific microorganisms constituted the indispensable and determining cause of particular clinical entities seemed to endorse the specificity of infectious disease-and thus by a kind of intellectual contagion, the notion of specific disease itself. Also supportive of such views was the growing prestige of what we have come to call the biomedical sciences: histology, biochemistry, physiology, and pharmacology. Collectively they spoke a reductionist, mechanism-oriented, and antivitalist language, providing a compelling and seemingly objective store of tools, procedures, models, and data that promised to delineate disease in newly precise, measurable-and thus portable-terms. The late-19th-century vogue for heredity and evolution constituted another significant factor, linking biology and behavior, mind and body, past and present. And many of the putative behavioral ills described in the late 19th century were in fact seen as constitutional. ${ }^{5}$ Alcoholism and homosexuality were prominent cases in point. Heredity seemed increasingly a determining-inexorable - force, rather than one among a variety of factors interacting to determine health and disease. Like the germ theory, heredity provided many late-19th-century physicians a reassuringly somatic mechanism with which to explain a variety of unsettling emotions and problematic behaviors.

\section{EXPANDING BOUNDARIES AND THE REDUCTIONIST PROJECT, 1870-1900}

Such explanations increasingly took the form of hypothetical disease entities, and neurasthenia was particularly prominent among such concepts (GijswijtHofstra and Porter 2001; Rosenberg 1962; Sicherman 1977). Coined in the late 1860 s by George M. Beard, a New York neurologist, the term neurasthenia incor-

\footnotetext{
${ }^{5}$ This instance implies a complex relationship between the notion of specific disease and that of patterned deviant behavior as a determined outcome of a general constitutional makeup. Fashionable degeneration theory provided a general framework for explaining such phenomena (Pick 1989).
} 
porated an eclectic mixture of symptoms: depression, anxiety, compulsions and obsessions, sexual dysfunction and deviance, and fleeting aches and pains both physical and mental. Although the concept might be thought in retrospect a forerunner of the 20th-century idea of neurosis - itself a catchall description for maladaptive individual adjustments in Freudian and post-Freudian models of personality and pathogenesis-Beard rationalized his discovery in relentlessly material terms. He had no choice if it were to be taken seriously by his peers: social legitimacy presumed somatic identity. In Beard's view, the elusive and ever-shifting symptoms that characterized neurasthenia were reflections of an underlying weakness in the individual sufferer's constitutional allotment of nervous energy. "Physiology," Beard (1884) explained, "is the physics of living things; pathology is the physics of disease" (p. 15). Although neurasthenia was characterized by feelings and behavior alone, Beard was confident that it rested on a firm if still obscure somatic basis. "I feel assured," he wrote in 1869, "that it [neurasthenia] will in time be substantially confirmed by microscopical and chemical examinations of those patients who die in a neurasthenic condition" (p. 218). The postmortem pathology that had so impressively delineated, for example, the lesions of tuberculosis and Bright's disease in the first half of the 19th century would soon illuminate this even more elusive but ultimately somatic condition.

This speculative somaticization of behavioral ills by physicians was, as we have seen, a medical tactic far older than Beard's Gilded Age "discovery" of neurasthenia. Hypochondria, for example, was as much the result of somatic causes as any physical ailment. Half a century earlier, Benjamin Rush (1812) had sought to combat the judgmental and widespread view that such ills were "imaginary," mere self-indulgence. Hypochondria, he explained, "has unfortunately been supposed to be an imaginary disease only, and when given to the disease in question is always offensive to patients who are affected with it. It is true, it is seated in the mind; but it is as much the effect of corporeal causes as a pleurisy, or a bilious fever" (p. 75).

Nineteenth-century physicians repetitively and formulaically referred to the brain as the organ of mind and mental illness as a product of brain disorder. ${ }^{6}$ What might be called the assumption of an ultimately somatic pathology had never been questioned in regard to the etiology of grave and incapacitating mental ills, but it had been broadened in scope by the late 19th century to include a variety of putative disease pictures that Rush and his generational peers would hardly have regarded as appropriate objects for clinical attention. In Beard's era of self-referred outpatient neurology, a variety of compulsions and obsessions, emotional pain (often termed mood disorders today), and what might be called

\footnotetext{
${ }^{6}$ This is not to obscure the early-19th-century physician's assumption that moral-emotionalcauses could over time bring about somatic change. Mind and body were continuously and necessarily interactive.
} 
problems of identity (as in homosexuality) began to populate that novel urban space, the consulting neurologist's waiting room.

It is not surprising that would-be ailments as diverse as homosexuality and railroad spine, anorexia and neurasthenia were all articulated in roughly the same period, the 1860s and 1870s. All were presumed to have some somatic if not constitutional basis, yet all explained behavior that seemed individually painful and dysfunctional, or socially problematic. Let me elaborate this argument with another example: the mid-19th-century ailment called "railroad spine" or "spinal concussion," diagnoses even less familiar today than neurasthenia. These novel diagnoses were associated with a growing mid-19th-century anxiety - and lawsuits-following the era's frequent railroad accidents. It reflected as well a widespread disquietude in confronting the seemingly unnatural and feverish pace of railroad travel. The pathological concept was associated with John Erichsen, a London surgeon, just as neurasthenia was associated with George Beard. Erichsen's On Railway and Other Injuries of the Nervous System (1866), originally a series of lectures given to students at University College Hospital, soon became a standard reference. And like Beard's formulation, Erichsen's diagnostic neologism reflected a more widespread sense of cultural uncertainty. Even before Erichsen's work, the Lancet had editorialized about the neurological sequalea of railroad trauma.

These symptoms are manifested through the nervous system chiefly, or through those physical conditions which depend upon the perfect physiological balance of the nerve-forces for their exact fulfilment. They vary . . f from simple irritability, restlessness and malaise after long journeys up to a condition of gradually supervening paralysis, which tells of the insidious disease of the brain or spinal cord, such as ... follows on violent shocks or injuries to the nervous centres. These latter are the symptoms which frequently ensue from the vehement jolts and buffetings endured during a railroad collision. (Harrington 2001, p. 42)

One can discern a rough filiation among neurasthenia, spinal concussion, soldier's heart, and shellshock, in a clinical tradition that linked particular clusters of emotional and behavioral symptoms with a parallel dependence on a legitimating (if in retrospect, hypothetical) physical mechanism. And all served in some measure as occasion and vehicle for social comment. It is no accident that George Beard wrote a much-cited book called American Nervousness (1881) and another on Sexual Neurasthenia (1884); both addressed widespread cultural anxieties about self and society.

Many novel late-19th-century entities such as sexual inversion and neurasthenia were soon adopted and widely cited but nevertheless remained controversial-to some clinicians and intellectuals real diseases, but to others mere self-indulgence or symptoms of a larger cultural decay. Diseases were deployed as rhetorical weapons in recurrent battles over cultural values and social practices. "Overstress," for example, was a condition noticed in late-19th-century second- 
ary schools and attributed to the urban middle class's relentless competitiveness, while sterility and hysteria could be seen as the inevitable cost incurred by higher education for women. An urban, technology-dependent - and thus unnaturallife could be stigmatized as psychically as well as physically pathogenic.

This all seems neat and tidy, with disease concepts mirroring and mediating both cultural angst and a widespread faith in the explanatory power of disease models. The dots are nicely connected. But the story on the ground is rather more complicated. These pathologizing tactics were neither universal nor consistently accepted in late-19th- and early-20th-century America. While many were attracted by the certainties of somatic and reductionist styles of explaining sickness and health, others found this approach less than congenial. Christian Science, consistently enough, like Spiritualism, Seventh Day Adventism, and the Emmanuel Movement, all developed in their several ways in tension with this polarizing development: at one pole a way of thinking about behavior reducible to somatic mechanisms (with an implied deterministic understanding of behavior), at the other pole a holistic, spiritual framework emphasizing faith and agency in their impact on health outcomes. One might think of them as two rather different styles of reductionism. Of course, many Americans-and not only lawyers - who shared a general faith in the progress of scientific understanding remained sceptical of the legitimacy and exculpatory implications of such would-be ills as alcoholism, kleptomania, anorexia, and nervous exhaustion; a parallel aura of ambiguity and disdain surrounded the older but still current diagnosis of hysteria. These behavioral and emotional ills and their presumed social causes echoed morally resonant controversies over class, appropriate gender behavior, and a variety of other issues — clashes in an endless cultural war in which we still struggle over the legitimacy of ills such as chronic fatigue syndrome, anorexia, fetal alcohol syndrome, alcoholism, and homosexuality, without arriving at a stable consensus.

\section{The More Things Change}

Some aspects of medicine's social history have changed dramatically in the past century; others comparatively little. One that has changed little is the mediating role of psychiatry. Medicine in general and psychiatry in particular remain boundary managers: border police examining and certifying transit documents in an unceasing battle over depression and anxiety, sexuality and addiction. Psychiatry remains the peculiar legatee of such problems, an obligate participant in every generation's particular cultural negotiations - a kind of canary at the pitface of cultural strife. It is by no means the only player. Civil and criminal courts, welfare officers, media commentators, a variety of other specialists-not to mention patients and families-all play a role.

The search for somatic mechanisms with which to legitimate behavioral ills seems in retrospect a parallel and logically related continuity. The 20th-century 
psychodynamic tradition with its emphasis on family setting and individual psychological development and associated talk therapies seems almost a kind of byway in relation to mainstream medicine, an oppositional-if culturally significant-counterpoint to a consistently dominant reductionism. Even at the height of its influence (from the 1940s through the 1970s), psychodynamic explanations of behavior and emotions remained in an uneasy and even marginal relationship to much of mainstream medicine, despite the widespread influence of such ideas outside the profession. That very marginality helps explain the recurrent attraction of intrusive therapies in 20th-century psychiatry (Braslow 1997; Pressman 1998; Scull 2005; Valenstein 1986, 1998).

The dominance of reductionist styles has a long history in the explanation of human behavior, but it has an extraordinarily salient place today. We have never been more infatuated with visions of molecular and neurochemical—ultimately genetic-truth. "We're now at the point where we can begin articulating the physical basis of some of the mysterious brain functions that exist . . learning, memory, and emotion. ... We're at a point where we can move miraculously from molecule to mind" (Wade 2001). In the not-too-distant past we have seen claims for the discovery of genetic bases for dyslexia, obesity, risk taking, homosexuality, even aggression. Many of us can remember the widespread discussion of chromosomal explanations for criminality. Today's fashionable evolutionary psychology adds a metahistorical style of biological reductionism to our culturally available store of mechanism-oriented and determinist explanations for behavioral and emotional pathologies (as well, of course, as the "normal").

But there remains an historical irony. We are in a moment of peculiar and revealing paradox, a complex and structured mix of reductionist hopes and widespread criticism of such sanguine assumptions. As a culture we are relentlessly reductionist in presuming somatic (and ultimately genetic) causation for behavior, yet at the same time we are reflexive, critical, and relativist in our approach to existing disease classifications and therapeutic modalities. We have never been more aware of the arbitrary and constructed quality of psychiatric diagnoses, yet in an era characterized by the increasingly bureaucratic management of health care and an increasingly pervasive reductionism in the explanation of normal as well as pathological behavior, we have never been more dependent on them. I need only underline the way in which the DSM has evolved from its originally modest format-a hundred-page spiral-bound, soft-covered form in 1952 and 1968 - to today's ponderous octavo (with its numerous epitomes, visual aids, and commentaries), while wry commentators lay and professional scoff at the seemingly transparent arbitrariness of its categories (Kirk and Kutchins 1992; Kutchins and Kirk 1997).

This inconsistency struck me, for example, with particular force in reading Girl, Interrupted, Susanna Kaysen's 1993 memoir of her late 1960s inpatient stay in McLean Hospital. The book includes a revealing section in which the author is seated in her "corner Cambridge bookstore" reading DSM III and decon- 
structing the substance and language of the borderline personality disorder diagnosis that had justified her treatment almost thirty years before (Kaysen 1993). She underlines the arbitrariness, the gender stereotypes, and the social control built into the seemingly objective language of clinical description. Kaysen's agnostic point of view reflects and incorporates three decades of political, epistemological, and feminist criticism of psychiatric nosology; there has never been a more sceptical and reflexive period. Explicit and fundamental criticism of psychiatric nosology has in fact been widespread for a half-century; one need only cite the works of Thomas Szasz, R. D. Laing, and a variety of feminist and sociological critiques of psychiatric authority and the epistemology that justified it.

The paradoxical reality of such fundamental skepticism coexisting with a triumphalist reductionism is exemplified as well in the current debate over the use of psychoactive drugs. In the past half-century, the widespread prescribing of such drugs implies and has helped legitimate the specific entity idea: bipolar disease is what responded to lithium; depression is legitimated ontologically by the drugs that treat it. But as current controversies over Ritalin and a variety of antidepressants and antipsychotic drugs, for example, suggest, these relationships have simply constituted a new site and designated players for the contestation of social values. Who would have guessed a generation ago that an American president would choose the pediatric use of psychoactive drugs as a public issue, as Clinton did during his presidency? And that we would accept with barely a second thought such public contestation of a seemingly clinical problem? ${ }^{7}$ Just as attention deficit was, for example, being widely discussed and accepted, it stimulated - through a kind of cultural dialectic - a variety of forceful rejections of such categories as arbitrary social constructions. It was not just that children and increasingly adults "are too casually offered stimulants like Ritalin," as a letter to the New York Times charged almost a decade ago, "but that biological reductionism lies behind the tendency to ignore the deeper social, psychological and cultural issues ... in favor of assuming there is a disease located within their heads" (Kohn and Armstrong 1997). Such critical sentiments may be in the minority, but they have been widely and articulately voiced in the past decade-with little effect (DeGrandpre 2000).

It is, of course, not simply a technical (pharmacological) problem, or a problem of diagnostic precision, or of pharmaceutical industry marketing strategies. No quantity of well-conceived epidemiological studies will bring consensus with regard to children exhibiting a problematic restlessness; it is at some level a problem of human diversity, of social class, of gender, and of bureaucratic prac-

\footnotetext{
${ }^{7}$ Of course, psychoactive drugs are not alone in attracting public debate. One thinks of the public debates over screening mammography or hormone replacement therapy — not to mention stemcell research - in the even more recent past, complete with newspaper editorials, op ed battles, full page ads, and television coverage.
} 
tice. Clinical epidemiological studies play a role, but as only one voice in a complicated and discordant discourse. Concepts such as hyperactivity are meaningful only in specific contexts. Even if the most extreme and intractable behaviors are ultimately products of still-undeciphered but ultimately specifiable genetic and neurochemical mechanisms, their social evaluation remains contingent and a subject of inevitable contestation. What are appropriate levels of attention? Of hyperactivity? What is normal and what is, in fact, being measured? When does therapeutics stop and enhancement begin? (Elliot 2003) The terms hyperactive or attention deficit are context-dependent by definition, reflections of specific institutional realities and cultural needs. And one of those needs, as I have suggested, is the recourse to medical personnel, authority, and conceptual categories as at once legitimation and framework for the institutional management and cultural framing of awkward social realities.

Similar judgments could be made in regard to a variety of such multicausal and nonspecific ills. A phenomenon such as fetal alcohol syndrome-like attention deficit hyperactivity disorder — might be thought of as a statistically configured point on a spectrum of behaviors and seemingly linked physical characteristics, perhaps reflecting an underlying biological substrate Even if we can define and defend such a core as constituting a usefully predictive entity, fetal alcohol syndrome, a presumably gestational phenomenon, would still serve as only one element in a more complex and multidimensional social reality. A disease entity so defined would incorporate not only the ideal-typical core of presumed victims of fetal alcohol syndrome, but also all the effects surrounding it. Like a stone dropped into a body of water, the ripples are real indeed, ranging from labels on alcoholic beverages, to individual guilt and anxiety, to pleas for reduced responsibility in criminal justice contexts-or, as we have seen, expanded responsibility placed on ethanol-addicted mothers (Armstrong 2003; Golden 2005). Depression constitutes a parallel and even more pervasive phenomenon. What we call "major depression" may have a biochemical substrate, but the relationship between etiology and individual clinical outcome remains obscure. How do we balance the determined and the contingent, the genetically given and the situationally negotiated? And what is the relationship between such disabling ills and the spectrum of emotional states we casually term "depression"? What is the gradient of that slippery slope from temperament and situational reaction to something rather different and categorically pathological? Laypeople today often put that functional distinction in linguistic terms when they say a person has a "clinical depression"-presumably an extreme point on the necessary spectrum of human pain and varieties of mood.

Despite such indeterminacy, our repertoire of specific entities constitutes a powerful reality, providing a resource for individuals in thinking about themselves and for society in conceptualizing behaviors, as can be indicated in the varied histories of such current and obsolete entities as hysteria, hypochondria, 
hypoglycemia, chronic fatigue syndrome, Gulf War syndrome, or gender identity disorder. There are scores of such problematic ills, and the very social utility of these categories implies their contestation. There are always winners and losers in the negotiations surrounding the attribution of such diagnoses, as the social legitimacy - and often social resources - associated with the sickness role constitutes a prize worth contesting. Advocacy groups and the Internet have only exacerbated such debates, as some individuals claim the sick role's legitimacy offered by certain controversial disease entities - chronic Lyme disease, for example, or chronic fatigue syndrome-while others scorn them as mere excuses for self-indulgence.

\section{CONFLICT AND CONTINUITY}

I have tried to describe a phenomenon that is always in process, always contested, and never completed. Sociologists and historians have described the linked phenomena of medicalization and bureaucracy as having mounted a powerful campaign for cultural and institutional authority over problematic behaviors and suspect emotions. And, in fact, the boundaries of presumed disease have in general expanded relentlessly in the past century and a half. But these boundaries remain contested even as they move outward. At least some medical and lay hearts and minds remain only partially converted to these new and expansive models of pathology.

This is only to have been expected. There are a number of continuities that guarantee both the continued centrality and contestation of behavioral and emotional ills. One such controversy turns on the paradox of using reductionist means for holistic — cultural_ends. As disease definitions have become more and more dependent on seemingly objective signs (first physical diagnosis, then laboratory findings and imaging results), ailments that cannot easily be associated with such findings were naturally segregated into a lesser status. Behavioral ills thus fall into a lowly position in a status hierarchy that is at once social, moral, medical, and epistemological. When allied with the fear, punitiveness, hostility, stigmatization, personal guilts, and pain often associated with such contested behaviors, it is hardly surprising that individuals exhibiting emotional and behavioral "symptoms" would not be consistently well-served by the mechanism-oriented specific-entity style of legitimating and conceptualizing disease. And when there is no cultural consensus - as in regard to homosexuality or substance abuse-there is no basis for a nosological consensus. But it is equally if ironically inevitable that the powerful concept of disease specificity has beenand will continue to be-employed as a tool for the ideological management of problematic emotions and behaviors. It is a tool, moreover, available to laypeople as well as clinicians and administrators. There is always an eager market for disease labels, whether found on a Web site, in a magazine, or in a nosological table. Insofar as our ideal-typical conception of disease is specific and mecha- 
nism-based, this reductionist model will remain to a degree inconsistent with the cultural — and, as I shall argue, bureaucratic - work performed through the articulation and deployment of such disease categories. ${ }^{8}$

A second factor is a never-ending negotiation over agency and responsibility. Post-19th-century models of disease bear with them an aura of determinism and can thus have a potentially significant role in shaping the social role allotted the sick. We want moral meaning in the narratives we impose on ourselves and others, and it is hard to find it in the random nemesis of genetics and neurochemistry. It is not only in the courtroom, but in society more generally that we seek to preserve responsibility for individual decisions (and thus meaning in misfortune). Contemporary debates over "obesity" represent an example of such ambiguity. Is it a disease or a failure of character? Does "it" represent the working out of genetic destiny, or does a predisposition toward weight gain constitute just one aspect of a complex and poorly understood biological and psychosocial identity? When does idiosyncrasy become pathology?

A third factor both nurturing the use of lexicons of disease categories and, at the same time, guaranteeing conflict about their definition and legitimacy are the linkages that structure medicine into a bureaucratized and highly institutionalized society. Each diagnosis links an individual to a network of bureaucratic relationships and often specialty practice. If it can't be coded, as the saying goes, it doesn't exist. But those coding decisions are potential sites of social contestation in which the legitimacy of individual diagnoses can become structured points of conflict and contestation. Linkage means connections, but differing institutional interests and practices breed conflict over policy, authority, and jurisdiction, as in the case of debates over workman's compensation or product liability, as well as the more obvious questions relating to disability or criminal responsibility. And, of course, individuals do not track neatly on to generalized disease categories and related practice guidelines. The potential arbitrariness of such clinical realities is often apparent to both physician and patient.

We may consign certain feelings and behaviors to the sphere of medicine, but medicine itself is not clearly bounded. Government policies on health care reimbursement, for example, or FDA regulatory procedures-like the (often not unrelated) corporate decisions of pharmaceutical companies in the private sectorhave in their various ways shaped disease definitions, accepted therapeutics, and thus individual experience. Powerful stakeholders are involved in all these decisions, and all relate ultimately to the clinical practices and legitimating concepts

\footnotetext{
${ }^{8}$ It is, of course, no easy matter to fit moods and behaviors into neat, defensible, and differentiable boxes, a point underlined in many critiques of the DSM. Moreover, the power of the specific entity ironically focuses clinical attention on any related states that might be construed as early stages of slippery slopes along the way to a full-blown disease. Anxieties and minor depressions are thus reshaped by their presumed relationship to well-marked conditions that they may signal (and possibly constitute), like hypertension or elevated cholesterol levels in cardiovascular disease.
} 
of contemporary medicine-and nowhere more markedly than in psychiatry. Consumer advertising as well as randomized clinical trials figure in the creation and diffusion of hypothetical disease entities, but the process is complex and elusive. Despite the expenditure of millions of advertising dollars, it is not clear, for example, that erectile dysfunction has been accepted as a legitimate, value-free, disease entity; it is still surrounded by a penumbra of stigma, whimsy, and selfconscious cultural irony.

Fourth, psychiatry and its concepts bleed constantly and unavoidably into the larger culture. This is a phenomenon by no means limited to the past century. I need only refer to the linguistic archaeology of once technical terms adapted into everyday discourse: nostalgia, hypochondria, sanguine, hysterical, paranoid, narcissism, degenerate, nymphomaniac, psychopath, inferiority complex, obsessive-compulsive. Usages have changed, but the process by which ordinary men and women appropriate once-technical medical language and explanatory frameworks to think about human behavior and its social management remains straightforward. Behavioral and emotional ills seem more accessible than "somatic" ills to laypeople, who often question such categories as depression or attention deficit but rarely interrogate and are generally unaware of the indeterminacy built into the diagnosis or staging of a somatic ill such as cancer.

Thirty years ago, I wrote an essay on what I called "The Crisis in Psychiatric Legitimacy" (Rosenberg 1975), in which I emphasized the difficult role played by psychiatrists and suggested that it would continue to be ambiguous, no matter what technical progress might take place: "Unless all psychiatry should thaw, melt, and resolve itself into applied pharmacology there seems little possibility of these difficulties redefining themselves" (p. 147). Perhaps psychiatry has in good measure resolved itself into applied pharmacology in the past three decades. But the range of human dilemmas that we ask medicine to address has if anything expanded, from depression to anxiety, from bereavement to dysfunctional marriage. So long as medicine in general and psychiatry in particular remains our designated manager of such problems, specific disease categories will always be an indispensable tool in the performance of that social role. So long as we ask medicine to help in doing the cultural work of defining the normal and providing a context and meaning for emotional pain, we will continue to fight a guerilla war on the permanently contested if ever-shifting boundary dividing disease and deviance, feeling and symptom, the random and the determined, the stigmatized and the deserving of sympathy.

\section{REFERENCES}

Armstrong, E.M. 2003. Conceiving risk, bearing responsibility: Fetal alcohol syndrome and the diagnosis of moral disorder. Baltimore: The Johns Hopkins Univ. Press.

Barnes, J. 2000. Insanity defense fails for man who threw woman on to track. NY Times, March 23. 
Bayer, R. 1987. Homosexuality and American psychiatry: The politics of diagnosis. Princeton: Princeton Univ. Press.

Beard, G. [M.] 1869. Neurasthenia or nervous exhaustion. Boston Med Surg J 80:21721.

Beard, G. M. 1881. American nervousness: Its causes and consequences. A supplement to nervous exhaustion (neurasthenia). New York: G. P. Putnam's.

Beard, G. M. 1884. Sexual neurasthenia [nervous exhaustion]: Its hygiene, causes, symptoms and treatment. New York: E.B. Treat.

Boston Globe. 2001. Letter to the editor, Feb. 20.

Braslow, J.T. 1997. Mental ills and bodily cures: Psychiatric treatment in the first half of the twentieth century. Berkeley: Univ. of California Press.

Clarke, A. E., et al. 2003. Biomedicalization: Technoscientific transformations of health, illness, and U.S. biomedicine. Am Sociol Rev 68: 161-94.

Conrad, P. 1976. Identifying hyperactive children: The medicalization of deviant behavior. Lexington, MA: Lexington Books.

Conrad, P. 2005. The shifting engines of medicalization. J Health Soc Behav 46:3-14.

Conrad, P., and J. W. Schneider. 1992. Deviance and medicalization: From badness to sickness. Philadelphia: Temple Univ. Press.

DeGrandpre, R. J. 2000. Ritalin nation: Rapid-fire culture and the transformation of human consciousness. New York: Norton.

Elliot, C. 2003. Better than well: American medicine meets the American dream. New York: Norton.

Erichsen, J. E. 1866. On railway and other injuries of the nervous system. London: Walton and Mabry.

Gijswijt-Hofstra, M., and R. Porter, eds. 2001. Cultures of neurasthenia: From Beard to the First World War. Amsterdam and New York: Rodopi.

Goldberg, C. 2005. Out of control anger. Boston Globe, Aug. 9.

Golden, J. 2005. Message in a bottle: The making of fetal alcohol syndrome. Cambridge: Harvard Univ. Press.

Grob, G. N. 1998. Psychiatry's holy grail: The search for the mechanisms of mental illness. Bull Hist Med 72:189-219.

Harrington, R. 2001. The railway accident: Trains, trauma, and technological crises in nineteenth-century Britain. In Traumatic pasts: History, psychiatry, and trauma in the modern age, 1870-1930, ed. M. S. Micale and P. Lerner, 31-56. Cambridge: Cambridge Univ. Press.

Healy, D. 1997. The anti-depressant era. Cambridge: Harvard Univ. Press.

Horwitz, A.V. 2002. Creating mental illness. Chicago: Univ. of Chicago Press.

Kaysen, S. 1993. Girl, interrupted. New York: Random House.

Kirk, S. A., and H. Kutchins. 1992. The selling of DSM: The rhetoric of science in psychiatry. New York: Aldine DeGruyter.

Kohn, A., and T. Armstrong. 1997. Letter to the editor. NY Times, Sept. 7.

Kriegman, G., R. D. Gardner, and D. W. Abse, eds. 1975. American psychiatry, past, present, and future: Papers presented on the occasion of the 200th anniversary of the establishment of the first state-supported mental hospital in America. Charlottesville: Univ. Press of Virginia.

Kutchins, H., and S. A. Kirk. 1997. Making us crazy: DSM, the psychiatric bible and the creation of mental disorders. New York: Free Press. 
McLean Hospital. n.d. The computer addiction service at McLean Hospital. Undated brochure. Belmont, MA.

New York Times. 1999. Equitable coverage for mental illness. June 10.

New York Times. 2002. Trial in case of drowned children opens. Feb. 2.

Paton, S. 1902. Recent advances in psychiatry and their relation to internal medicine. Am J Insanity 58:433-42.

Pick, D. 1989. Faces of degeneration: A European disorder, circa 1848-circa 1918. Cambridge: Cambridge Univ. Press.

Pressman, J. D. 1998. Last resort: Psychosurgery and the limits of medicine. Cambridge: Cambridge Univ. Press.

Rosenberg, C. E. 1962. The place of George M. Beard in nineteenth-century psychiatry. Bull Hist Med 36:245-59.

Rosenberg, C. E. 1975. The crisis in psychiatric legitimacy: Reflections on psychiatry, medicine, and public policy. In American psychiatry, past, present, and future: Papers presented on the occasion of the 200th anniversary of the establishment of the first state-supported mental hospital in America, ed. G. Kriegman, R. D. Gardner, and D. W. Abse, 135-48. Charlottesville: Univ. Press of Virginia.

Rosenberg, C. E. 1995. Banishing risk: Or the more things change the more they remain the same. Perspect Biol Med 39:28-42.

Rosenberg, C. E. 2002. The tyranny of diagnosis: Specific entities and individual experience. Milbank Q 80:237-60.

Rosenberg, C. E. 2003. What is disease? In memory of Owsei Temkin. Bull Hist Med 77: 491-505.

Rush, B. 1812. Medical inquiries and observations, upon the diseases of the mind. Philadelphia: Kimber \& Richardson.

Sicherman, B. 1977. The uses of diagnosis: Doctors, patients, and neurasthenia. J Hist Med $32: 33-54$.

Scull, A. 2005. Madhouse: A tragic tale of megalomania and modern medicine. New Haven:Yale Univ. Press.

Valenstein, E. S. 1986. Great and desperate cures: The rise and decline of psychosurgery and other radical treatments for mental illness. New York: Basic Books.

Valenstein, E. S. 1998. Blaming the brain: The truth about drugs and mental health. New York: Free Press.

Wade, N. 2001. The other secrets of the genome. NY Times, Feb. 18. 